\title{
INSTITUIÇÕES ESCOLARES: MEMÓRIA, FONTES E ARQUIVOS
}

\author{
João Carlos da Silva ${ }^{1}$ \\ Eraldo Leme Batista ${ }^{2}$ \\ Lidiane Maciel Mafatto ${ }^{3}$ \\ Anderson Szeuczuk ${ }^{4}$
}

\section{RESUMO}

Discute elementos históricos a partir do campo temático, denominado história das instituições escolares. O desafio do trabalho do historiador da educação consiste num esforço constante de fazer as fontes falarem sobre os homens e a sociedade. A qualidade do conhecimento histórico depende da relação do pesquisador com as fontes quando este não precisar tomar boa parte do tempo da pesquisa para localizá-las nos arquivos. Dedicar-se ao estudo da história das instituições escolares, requer compreender sua materialidade em seu interior e em seu entorno, a partir de um olhar histórico por meio das relações que se estabelecem no interior da sociedade.

Palavras-chave: História da educação; arquivos; memória

\section{INSTITUTIONS SCHOOL, MEMORY, SOURCES AND ARCHIVES}

\begin{abstract}
Discusses historical elements from the subject field, called the history of schools. The challenge of education historian's work is a constant effort of making the sources talk about men and society. The quality of historical knowledge depends on the researcher's relationship to the sources when it need not take much time from research to locate them in the archives. Devote himself to the study of the history of educational institutions, requires an understanding of its material in its interior and its surroundings, from a historical look through the relationships established within society.
\end{abstract}

Keywords: History of education; files; memory

\section{Introdução}

No século XIX, com a Revolução Industrial, a constituição da sociedade de classes sociais provocou o aprofundamento da divisão do trabalho, cenário em que se deu a institucionalização da escola contemporânea. Neste cenário, a escola, considerada lugar do ócio, na Grécia Antiga, para aquela classe livre do trabalho braçal, estrutura-se, de um lado, aos que dispõem de tempo, de outro, aos que foram encaminhados ao trabalho.

Como instituição, a escola foi se complexizando ao longo da história, sobretudo a partir do século XX, como espaço de disseminação de discursos e projetos políticos, para alcançar determinados fins em uma ordem social. Compreender a historia da educação também perpasse pela preservação os documentos escolares. A memória da escola é representada pelos objetos e pelas relações interpessoais. A situação precária dos acervos das escolas por razões diversas é conhecido pelos profissionais da área. 
Este artigo procura pontuar alguns elementos a partir do campo temático, denominado história das instituições escolares, organizado em dois tópicos principais. Inicialmente faremos alguns apontamentos sobre os arquivos e sua importância na pesquisa histórica. Em seguida discutiremos aspectos referentes ás fontes, os desafios e perspectivas do estudo das instituições escolares no conjunto da pesquisa histórico-educacional.

\section{Arquivos na pesquisa documental}

Um dos problemas mais evidentes nos arquivos consiste na eliminação indiscriminada dos documentos escolares, isto acontece menos pela ausência de normas legais que regulamentam, do que pela preservação dos documentos. $\mathrm{O}$ conhecimento da documentação visa levar a comunidade escolar a compreender a importância na reconstrução da memória institucional.

A preocupação em relação á importância dos conhecimentos arquivísticos é recente e pouco disseminada. Deve-se principalmente pela ausência de uma prática e valorização das fontes primárias. Essa perspectiva impõe aos pesquisadores ao desafio da preservação das fontes históricas em arquivos públicos e a constituição dos arquivos escolares.

A rigor, o documento histórico é um discurso sobre a realidade, interpretado pela leitura do historiador, que lhe acrescenta os envolvimentos e inquietações do presente. Problematizar o documento como objeto de construção histórica significa aprender sua historicidade, o que conduz a uma acepção alargada do documento educacional.

Nas documentações sobre a vida escolar existem informações fundamentais sobre estudo da origem e atribuições das escolas encontradas nos estatutos e regimentos. Os prontuários dos alunos e os Livros de Matrículas trazem dados sobre filiação e nacionalidade dos alunos e profissão dos pais. O Livro de Ponto e o Livro de Frequência indicam os nomes de professores e funcionários admitidos. As Atas de Diretoria e os Relatórios contêm dados importantes sobre o funcionamento institucional e suas transformações.

Nosella e Buffa (2006), alertam sobre os riscos metodológicos deste tipo de pesquisa, ao garantir um envolvimento do pesquisador, podendo secundarizar a compreensão da totalidade histórica, e neste sentido omitir o movimento real da sociedade. Este desafio certamente exige por parte do pesquisador um maior cuidado na aplicação do método dialético. Entretanto tal dificuldade, não significa subestimar as contribuições destas novas metodologias de pesquisa que buscam no particular os elementos para compreender e desvelar a realidade.

\section{A história da educação e as inovações historiográficas}

Na última década, têm predominado na historiografia da educação brasileira categorias da chamada Nova História, uma história que tenha como parâmetro a totalidade social, mas uma história que tem como universo de investigação o "micro". Novos teóricos têm fundamentado tal historiografia entre eles: Roger Chartier, Foucault, Guinsburg, Le Goff, entre outros. Esta tendência foi vista como um arejamento da historiografia da educação brasileira, ao levantar novas categorias de análise como: representações, mentalidades, imaginário social, memória etc.

Acreditamos ser necessário enfrentarmos estes desafios epistemológicos no campo da história da educação, buscar subsídios para compreendermos o pensamento pedagógico, das instituições educacionais e das práticas educativas, buscando 
simultaneamente os determinantes dos processos educativos e a especificidade da educação em cada contexto histórico.

Dosse (2003) considera que a história nada mais é do que o trabalho dos documentos. A história neste sentido tornou-se uma ciência a reboque dos documentos A Primeira Guerra produziu uma crise global, instaurando incertezas acerca do papel do historiador e enfraquecimento da história política e econômica Os Annales propunham um alargamento das fontes, dos métodos até então não explorados, saindo das fontes oficiais. Mantiveram uma preocupação totalizante, mas sem perder de vista o local. Passaram a valorizar as lutas não apenas coletivas, mas individuais, não somente do geral, mas do particular. O historiador deve apropriar-se de outros campos, atentando para o que não está dito nos documentos, buscando uma história problema. Nesta abordagem, a história é entendida como uma enciclopédia, em que tudo deve ser estudado, todas as manifestações, buscando diferentes laços existentes na trama do real.

As transformações no conceito de fontes pela escola dos annales, influenciou o pensamento historiográfico contemporâneo, possibilitando uma ampliação no objeto do historiador, contando com uma diversidade de fontes, anteriormente desconsideradas, entre elas as orais, escritas ou visuais. Percebemos uma "ampliação de paradigmas", que deveriam ir muito além do político e do econômico (REIS, 2000).

$\mathrm{Na}$ pesquisa sobre a história das instituições escolares diferentes categorias são utilizadas: livros de chamada e de atas, antigos cadernos, livros didáticos e cartilhas, bem como fotografias e outros objetos de uso cotidiano nas escolas da época. O imaginário de ex-alunos e a história das instituições, da educação indígena, dos negros, das mulheres; do mobiliário, da arquitetura escolar, dos métodos pedagógicos, do currículo e das ideias pedagógicas.

Novas operações historiográficas demonstram que os estudos do micro devem visar compreender o macro, levantando os elementos que escapam a totalidade. Não se trata, assim de estudar região em sua singularidade, mas entender o macro, em sua riqueza de detalhes.

Esta história de novo tipo, esta "arqueologia", como lhe chamou o seu inventor, "desdobra-se à dimensão de uma história geral"; não se especializa na prática, o discurso, a parte oculta do iceberg, ou melhor, a parte oculta do discurso e da prática

Não é separável da parte emersa" (LE GOF, 1994, 384-85).

A melhor prova de que a história é, e, deve ser uma ciência é o fato de precisar de técnicas, de métodos, e de ser ensinada. Investigação não é um assunto do próprio historiador mas de auxiliares que constituem reservas de documentos onde o historiador escolherá a sua documentação: arquivos, investigações arqueológicas, museus, bibliotecas, etc. As perdas, a escolha dos compiladores de documentos, a qualidade da documentação são condições objetivas, mas limitativas do ofício de historiador. Mais delicados são os problemas que se põem ao próprio historiador a partir desta documentação. Le Gof ainda diz que:

Toda a história é arqueologia por natureza e não por escolha: explicar e explicitar a história consiste em começar por apercebê-la na sua totalidade, conduzir os pretensos objetos naturais às práticas datadas e raras que os objetivam e explicar essas práticas, não a partir de um motor único, mas de todas as práticas vizinhas em que se apóiam. (LE GOF, 1994, p.87).

A maior ambição do historiador consiste em analisar os fatos procurando compreendê-los com maior exatidão possível, com estudos minuciosos dos textos escritos, não buscar na imaginação ou nas suposições. 
A história deve perscrutar as fábulas, os mitos, os sonhos da imaginação, todas essas velhas falsidades sob as quais ela deve descobrir alguma coisa de muito real, as crenças humanas. Onde o homem passou e deixou alguma marca da sua vida e inteligência, aí está a história. (LE GOF, 1994, p. 88)

A história fez-se, sem dúvida, com documentos escritos, já dizia Bloch, mas quando existem. É possível fazer sem documentos escritos, naquilo que a inventividade do historiador permitir para fabricar seu alimento que ira nutrir sua descoberta. Tudo aquilo que o homem escreve, diz, fabrica ou marca ai esta sua inteligência, seu vestígio.

Questionar as estruturas do poder de uma sociedade, os setores e grupos sociais que orientavam para onde a história devia caminhar, isto é, o poder sobre a memória futura, tudo deve ser reconhecido e desmontado pelo historiador. Não existe documento inocente, cabendo ao pesquisador a capacidade de discernir o que é "falso", e o que é "verdadeiro" desmistificando e verificando sua credibilidade. A rigor, passam a ser fontes históricas somente após serem transformados a sua função em confissão de verdade. (LE GOF, 1994)

É sabido que os documentos somente falam se lhes pedem que confirmem. A rigor a pergunta que constrói o objeto de pesquisa. "Rastro, documento e pergunta: são os tripés do conhecimento histórico" (RICOUER, 2007, p. 188.).

$\mathrm{O}$ documento se torna enquanto tal, somente quando procurado, encontrado, construído, instituído, questionado por um feixe de perguntas e rastreado no estudo e na análise. Documento, pois, é tudo aquilo que pode ser questionado com a finalidade de encontrar algumas informações sobre o passado, a partir de um olhar sempre desconfiado acerca de certas afirmações cristalizadas, onde o verdadeiro ou o falso são colocados a prova.

A rigor, os homens precisam das instituições, para se servirem, como mediadores de seus conflitos e de suas necessidades. A memória é uma fonte de história e conhecimento e não uma mera reminiscências daquilo que nos causou dor , prazer sofrimento. Marc Bloch (2001) em Apologia a historia, ou o oficio do historiador, sai em defesa da história e do historiador como profissional, valorizando a memória como uma das matérias primas da história.

Para ele, o historiador deve ser faminto, um devorador de historia, dialogar com a sociologia, mas sem confundir com esta. Os estudos exploratórios e dialéticos têm revelado grande potencial criativo de pesquisa, fazendo emergir propostas inovadoras no campo da história da educação. Dessa forma, a historiografia surge como sequiência de novas leituras do passado, plena de perdas e ressurreições, falhas de memória e revisões.

Estas atualizações também afetam o vocabulário do historiador, introduzindo-lhe anacronismos conceituais e verbais, que falseiam a qualidade do seu trabalho. Em primeiro lugar, porque há pelo menos duas histórias: a da memória coletiva e a dos historiadores. A primeira é essencialmente mítica. O desejável é que a informação histórica, fornecida pelos historiadores de ofício, vulgarizada pela escola (ou pelo menos deveria sê-lo) e os mass media, corrija esta história tradicional falseada. A história deve esclarecer a memória e ajudá-la a retificar os seus erros. Como nos alerta Le Gof, todo o documento é um monumento ou um texto, e nunca é "puro", isto é, puramente objetivo.

\section{Desafios na pesquisa histórica}

A história constitui-se com fontes, muitas vezes a análise do passado torna-se um desafio ao trabalho do pesquisador que ao procurar compreender um determinado contexto 
histórico depara-se com a escassez de documentação. Em outros casos, a abundância de fontes, acaba colocando o pesquisador em uma "encruzilhada", ao qual tem a decidir pelo o que privilegiar ou o que descartar.

A pesquisa histórica surge de "achados", de novas fontes, metodologias, comparações e conexões, ou até mesmo, as insatisfações e inquietações que o pesquisador depara-se em sua trajetória acadêmica. Com isso, uma problemática inicial poderá sofrer outros desdobramentos até a conclusão do trabalho.

Lara (2008) chama atenção acerca da importância de adotar certos protocolos no tratamento interno da fonte documental, ao ter a fonte como peça textual: Deve-se buscar, não somente o que foi escrito, em sua singularidade, mas para quem foi escrito, como foi escrito, para que foi escrito, como este documento circulou e foi guardado. Tudo isso são fontes de informação para os historiadores. Assim cabe ao historiador transformar um texto em documento-textual, desde que levando todos esses elementos em conta. Necessidade de confrontar as diferentes versões do documento.

As fontes são essenciais para interpretação e compreensão do fato histórico, sua conservação e acesso por parte do pesquisador são fundamentais para escrita da história. A sociedade como um todo, não tem o hábito de valorizar e preservar os "vestígios do passado", isso se deve tanto pela falta de conhecimento, como pelo senso comum de que tudo que é "velho" precisa ser descartado.

Uma pesquisa deve partir de um planejamento a qual dará ao pesquisador o respaldo e encaminhamentos necessários para o estudo de seu objeto, é preciso saber de "onde sair', para saber "onde se quer chegar". Planejar uma pesquisa é de certa forma, prever as etapas a qual um trabalho irá passar e os possíveis desdobramentos da mesma.

O objetivo de uma pesquisa deve ser a produção do conhecimento que ultrapasse o senso comum, devendo primeiramente ser procedida por um tema e um problema. Para isso se faz necessário, ao adentrar em uma pesquisa histórica, um projeto ou ao menos um esboço dos procedimentos metodológicos que serão abordados no trabalho.

A primeira etapa de um trabalho de pesquisa é a existência de um problema, afinal "sem problema não há pesquisa". Aróstegui destaca; "é o problema o que condiciona as fontes" (ARÓSTEGUI, 2006, p. 490). Tal desafio, muitas vezes surge após uma catalogação, observação e análise de uma determinada documentação, a partir deste problema o pesquisador direcionará seu trabalho, pois é o problema que condiciona as fontes, mas também as fontes podem condicionar o problema, na medida da escassez de algumas e abundância de outras direcionam o trabalho para outros caminhos.

O recorte temporal é um elemento fundamental, visto que, "não se pode pesquisar tudo", partindo deste pressuposto, faz-se necessário um recorte temporal, ou seja, qual o tempo e periodização que será pesquisado? Este ponto deve ser analisado com muita minúcia e dependerá muitas vezes das fontes a disposição do pesquisador, a qual sua própria datação, servirão como diretrizes para o encaminhamento do trabalho.

O recorte espacial também é um elemento importante, entende-se por este a localização espacial da pesquisa, que poderá ser uma revisão em um âmbito internacional, nacional, estadual, municipal, regional ou local. Sem dúvida que pesquisas mais abrangentes, são evitadas pela maioria dos "aventureiros". Isso justificando-se atualmente, pelo curto tempo ao qual os estudantes e pesquisadores dos programas de pós-graduação são submetidos.

Uma pesquisa regional ou local com uma periodização bem definida e delimitada, terá mais chances de sucesso e com um resultado mais satisfatório, que uma pesquisa mais ampla que tente abordar a "totalidade". Porém, um recorte espacial e temporal muito 
reduzido pode limitar os resultados esperados para o trabalho final, com isso, cabe ao historiador essa mediação entre tempo disponível e limitação das fontes.

Toda pesquisa parte de perguntas que dirigem o pesquisador a possíveis respostas, e com isso favorecem cada passo do prosseguimento do trabalho. $\mathrm{O}$ historiador busca mesmo inconscientemente a justificativa de o "porquê" de um elemento do passado. É possível que uma pesquisa se detenha, na explicação e descrição de um fenômeno específico, ou mesmo na análise e interpretação de um fato.

Atualmente contamos com uma diversidade de fontes que podem ser utilizadas pelos historiadores. Na história da educação podemos destacar a possibilidade do trabalho com diversas fontes, as que são produzidas internamente pelas instituições de ensino como; atas, cartas, caderno de alunos, documentação de alunos, fotografias, gravações, notas financeiras, relatórios das instituições, projetos políticos pedagógicos, planos de trabalho dos docentes, livros ponto de funcionários e outros documentos que ficam de posse da instituição.

Não existe um caminho único para adentrar na pesquisa sobre instituições escolares, o pesquisador pode fazer isso pelo currículo, pela legislação, pela proposta educacional, pelo quadro de alunos e de professores, pela arquitetura, enfim existem diversas formas de iniciar o trabalho sobre uma instituição, afinal serão as perguntas e questionamentos que direcionaram este trabalho.

O historiador quando pretende analisar uma determinada instituição educativa, tem a possibilidade de compreender as múltiplas dimensões que contornam a sua constituição e presença na sociedade em um determinado período histórico, podendo observar como se deu o processo de construção de identidade de uma instituição de ensino em uma determinada sociedade. Para isso, as fontes são fundamentais, como foram produzidas sem a intenção de servirem de documentação para pesquisa, necessitam na analise e interpretação do pesquisador.

Nas instituições escolares, preserva-se a documentação pertinente aos interesses burocráticos do sistema educacional, tais como a documentação pessoal de funcionários e de alunos, descartando-se em sua maioria a documentação vista como "desnecessária" aos interesses da legislação. Ao adentrar na pesquisa sobre uma instituição, o pesquisador percebe que a maioria das fontes já se perdeu, na medida em que a documentação referente a determinadas particularidades foi descartada ou extraviada:

No interior das instituições há um quebra-cabeça a ser decifrado. Uma vez dentro da instituição, trata-se de se fazer o jogo das peças em busca dos seus respectivos lugares. Legislação, padrões disciplinares, conteúdos escolares, relações de poder, ordenamento do cotidiano, uso dos espaços, docentes, alunos e infinitas outras coisas ali se cruzam. Pode-se dizer que uma instituição escolar ou educativa é a síntese de múltiplas determinações, de variadíssimas instâncias (política, econômica, cultural, religiosa, da educação geral, moral, ideológica etc.) que agem e interagem entre si,"acomodando-se" dialeticamente de maneira tal que daí resulte uma identidade. (SANFELICE, 2007, p.77)

O pesquisador tem uma diversidade de fontes que pode ser utilizada, o trabalho do pesquisador pode concentrar-se apenas com as fontes produzidas internamente pela instituição. Nas palavras de Sanfelice (2007, p. 78). "Nenhuma instituição manifesta sua identidade plena apenas no interior dos seus muros, por isso é fundamental olhar para o seu entorno". 
Para entendermos a conjuntura das relações sociais e políticas que tangem a constituição de uma Instituição, faz-se necessário este olhar "ampliado", buscando em fontes externas a instituição tais como a documentação oficial Leis, Projetos de Lei, Ementas na legislação, Mensagens de governo, relatórios de governo e demais documentos que são produzidos pelas esferas governamentais e tangem aspectos educacionais.

Sobre isso, Rodríguez destaca :

É fundamental desenvolver uma metodologia que permita entender as contradições internas da estrutura social dos diferentes períodos históricos, com o intuito de estudar essas ondas em suas diversas oscilações, facilitando a reconstrução das relações entre estrutura e superestrutura e entre o desenvolvimento do movimento orgânico e do movimento da conjuntura. Dado que a história é um processo contínuo, constituído por rupturas e descontinuidades, e não uma mera somatória de fatos, o estudo histórico é entendido como uma construção social, e não uma sucessão linear de fatos (RODRÍGUEZ, 2010, p.36).

Para que um entendimento e a compreensão mais aproximada do que as fontes informam, é preciso que o mesmo tenha o cuidado em considerar o interior de sua história e também ampliar o seu contexto. A percepção da história investigada pode conter relações com outra história mais ampla do qual não está situada.

Em relação aos arquivos documentais, mais especificamente na área educacional, a maioria das instituições de ensino têm um lugar reservado para armazenar os documentos. Assim, o historiador quando se dirige as fontes pode encontrar ou não informações relevantes para os estudos do período investigado.

A partir dessa compreensão Rodríguez menciona que:

A periodização resulta de uma reflexão sobre permanências e mutações nos modos de produção e nas formas de organização que as sociedades adotam num dado espaço e tempo. Assim, em cada período histórico são produzidos inúmeros documentos que dão conta do processo histórico. É primordial observar e definir claramente que tipos de documentos serão analisados para entender um dado período histórico (RODRÍGUEZ, 2010, p.41).

Ao questionar o documento, o historiador traz o processo de construção histórica para a compreensão que conduz uma elaboração amplificada do documento. Esta tarefa leva o pesquisador na procura de dados que proporcionam tal compreensão, com propriedades de relevância na elaboração de reconstrução histórica, decifrar memórias sociais e educacionais envolvidas na formação daquela sociedade estudada.

Quando o historiador encontra suas fontes em estado precário de guarda e sem identificação do que se trata cada documento, normalmente ele terá que utilizar mais tempo para organizar e posteriormente fazer o uso. As pesquisas com fontes primárias na maioria das vezes mostram a necessidade de maior disposição e exigem maior cuidado no manuseio e leituras para suas análises.

A exploração das fontes é uma das tarefas fundamentais para uma pesquisa, pois ela pode ser o eixo essencial sobre a qual se construirá os estudos e a pesquisa histórica.

Conforme, Borges:

São os homens que fazem a história; mas, evidentemente, dentro das condições reais que encontramos já estabelecidas, e não dentro das 
condições ideais que sonhamos. Eis aí a razão de ser, a justificativa da história, em seu segundo sentido: o conhecimento histórico serve para nos fazer entender, junto com outras formas de conhecimento, as condições de nossa realidade, tendo em vista o delineamento de nossa atuação na histórica (BORGES, 1993, p.48).

Neste sentido, percebemos que os estudos na história da educação estão ligados com o processo da dialética, onde cada pratica social possui um princípio em sua própria contradição, formando uma nova história. Analisando esta questão, nos adentramos nas instituições escolares e o seu relacionamento com as pesquisas históricas.

\section{Instituições escolares e a pesquisa histórica}

A recuperação das fontes nas instituições escolares está se destacando conforme apresentam as manifestações dos sujeitos ou de grupos, que fazem parte de um determinado contexto histórico, por conseguinte, relevante para o entendimento da história de uma determinada sociedade.

Nestas circunstâncias, verificamos que muitos dos arquivos das instituições escolares se encontram abandonados, como papéis empilhados em armários, sem nenhuma preocupação do devido acondicionamento para que não deteriore e prolongue o seu uso. Assim, o nome dado como arquivo morto para o amontoado de papéis se torna um velho conhecido dos funcionários das escolas.

Geralmente, os arquivos escolares se localizam em salas inutilizadas, esquecendo que por meio destes documentos se encontram informações que caracterizam todo um tempo histórico demarcado por uma determinada sociedade.

Em muitos dos documentos educacionais, podemos identificar características que remetem à organização da sociedade, incluindo até mesmo a própria legislação vigente no período.

Relacionando a educação com as atividades da sociedade, Romanelli esclarece:

Em primeiro lugar, cremos poder tranquilamente afirmar que a organização da educação em determinada sociedade é, antes de tudo, um problema de ordem política. Essa afirmação decorre do fato de que a organização se faz através da legislação, e esta, votada pelo legislativo ou apenas decretada pelo executivo, depende sempre do poder real de quem a vota ou decreta e da representação própria desse poder e emanada das camadas sociais existentes. Enfim, a legislação é sempre o resultado da proposição dos interesses das classes representantes no poder (ROMANELLI, 1983, p.188).

Destacamos então, que os documentos presentes nos arquivos escolares são valiosos para a pesquisa histórica. Eles portam dados locais e culturais do período em que foram produzidos, possibilitando a identificação de como se deu o crescimento e desenvolvimento naquele tempo, a formação de novos grupos e classes sociais.

Os documentos históricos são ferramentas fundamentais para os historiadores, assim produzem as interpretações históricas, como desvendar um enigma que se transformando e se caracterizando para a conclusão do seu movimento histórico.

Rodríguez contribui: 
Portanto, a produção do documento não se fecha em si mesma; ela está contextualizada e adquire conotação histórica à medida que reflete ou explica um fato e um tempo específicos da produção humana, seja ela material ou simbólica (RODRÍGUEZ, 2010, p.43).

Esclarecemos que, a qualidade da produção histórica esta diretamente ligada na presença das fontes e suas compreensões. O relacionamento concreto com os documentos, se torna possível, quando o pesquisador não tenha a necessidade de utilizar boa parte de seu tempo para antes localizar e identificar suas fontes. Assim a importância de encontrar os documentos já catalogados e identificados para a qualidade de futuras pesquisas.

É árduo o trabalho do pesquisador, mesmo que aparentemente muitos considerarem que é uma tarefa teórica, nos atentamos que ao realizar, temos a necessidade de atenção rigorosa e um conhecimento prévio, pois, as características e cada detalhe que o documento traz, pode ser decisivo para tal interpretação.

Borges, nos lembra que:

Um historiador, ao se propor fazer uma pesquisa, já faz uma opção bem sua, ao decidir qual o objeto que ele vai estudar. Sua escolha é sempre encaminhada pela sua situação concreta. O historiador é um homem em sociedade, ele também faz parte da história que esta vivendo. Escreve sua história historicamente situado, ou seja, numa determinada época, dentro de condições concretas de sua classe, sua instituição de ensino ou pesquisa, etc. seu trabalho será condicionado tanto pelo nível de conhecimento então existente, pelos interesses que ele possa estar defendendo, mesmo que inconscientemente (BORGES, 1993, p.65).

Todo desdobramento sistematizador necessita de um desprendimento com as características pessoais do historiador, é indispensável que se preocupe em estabelecer o mais próximo do aspecto sócio, cultural e político, observando as individualidades e não descartando as relações materiais e históricas.

Ao questionar as fontes como instrumento para a elaboração histórica do que se busca construir, significa compreender a sua historicidade, que leva o historiador para o entendimento amplo do documento analisado.

\section{Considerações finais}

A proposta de resgate da reconstrução histórica das Instituições Escolares defrontase com dois problemas presentes nas investigações da História das Instituições Escolares, a saber: o trabalho de levantamento, catalogação de fontes diante das precárias condições de armazenamento nas escolas públicas e o trabalho de articulação dos diversos tipos de fontes, de modo a não deixar escapar as características e o significado do fenômeno investigado (SAVIANI, 2004)

O processo de resgate das fontes das Instituições Escolares e de escrever a história destas Instituições amplia as possibilidades de compreensão da própria História da Educação, na medida em que elas se relacionam com o todo, não sendo mera subdivisão da educação. A reconstrução histórica depende essencialmente das fontes, que são o ponto de origem, a base e o ponto de apoio para a produção historiográfica.

As fontes das Instituições Escolares ganham significados na medida em que traz a expressão de sujeitos ou grupos sociais específicos, que representam um contexto histórico determinado, sendo relevantes para compreensão da História da Educação de uma 
sociedade. No entanto, temos verificado em pesquisas anteriores, que a situação de manutenção das fontes pelas escolas públicas não é muito diferente da maioria dos acervos de Instituições Escolares do restante do país, com documentação dispersa, sem qualquer acondicionamento, deteriorando-se e sendo perdida.

As Instituições Escolares, salvo pouquíssimas exceções, não têm a cultura que leve a uma prática continua de preservação de fontes. Encontramos com freqüência a existência do arquivo morto como um amontoado de papéis, caixas velhas, instalados em cubículos, porões ou banheiros quebrados, onde a poeira, a umidade e as traças se encarregam de executar a deterioração do material.

Diante desta realidade vimos a necessidade de concentrar esforços no sentido da pesquisa histórica regional e que se realize o resgate das fontes, bem como, se consiga o envolvimento das escolas na preservação da memória institucional da Escola Pública.

Desta forma, o nosso empenho é de criar as condições objetivas para a preservação das fontes das Instituições Escolares selecionada para esta pesquisa, que possibilitem ao historiador buscar a explicitação da singularidade e da identidade histórica das Instituições Escolares.

Dedicar-se ao estudo da história das instituições escolares, requer identificar a noção de cultura escolar ou cultura da escola, que existe em seu interior e quais as relações desta cultura com a cultura vigente da sociedade. Reconhecer estas manifestações culturais, implica em conhecê-las em sua totalidade, a partir de um olhar histórico, para que desta maneira a instituição seja compreendida por meio das relações que se estabelecem no interior da sociedade.

\section{Referencias}

ARÓSTEGUI, J. A pesquisa histórica: teoria e método. Bauru: Edusc, 2006.

BLOCH, Marc. (2001). Apologia a história, ou o oficio do historiador. Rio de Janeiro: Zahar, 2001.

BORGES, Vavy Pacheco. O que é história. São Paulo, SP: Brasiliense, 1993.

DOSSE, François. A história em migalhas: dos annales á nova história. Bauru, SP; EDUSC, 2003

LARA, Silvia Hunold. Os documentos textuais e as fontes do conhecimento histórico. Revista Anos 90. Porto Alegre. Vol. 15. N. 28. Dez. 2008.

LE GOFF, Jacques. História e Memória. Campinas: Ed. UNICAMP, 1994.

NOSELLA, Paulo; BUFFA, Ester. As pesquisas sobre instituições escolares: balanço crítico. In. II Colóquio sobre Pesquisa de Instituições Escolares UNICAMP/Campinas/UNINOVE, São Carlos. 2006

RICOUER, Paul. A memória, a história o esquecimento. Campinas, SP. Editora UNICAMP, 2007.

ROMANELli, Otaíza de Oliveira. História da educação no Brasil. Petrópolis, RJ: Vozes, 1983. 
RODRÍGUEZ, Margarita Victoria. Pesquisa Histórica: $\mathrm{O}$ trabalho com fontes documentais. In: COSTA, C.J.; MELO, J.J.P.; FABIANO, L.H. (orgs). Fontes e métodos em história da educação. Dourados, MS: Ed. UFGD, 2010.

NASCIMENTO, Maria Isabel Moura; SANDANO, Wilson; LOMBARDI, José Claudinei; SAVIANI, Dermeval (orgs.) Instituições Escolares no Brasil: conceito e reconstrução histórica. Campinas, SP: Autores Associados: HISTEDBR; Sorocaba, SP: UNISO; Ponta Grossa, PR: UEPG, 2007.

SAVIANI, D. Breves considerações sobre fontes para a História da Educação. In.LOMBARDI, José Claudinei; NASCIMENTO, Maria Isabel Moura (orgs.). Fontes,história e historiografia da educação. Campinas, SP: Autores Associados, 2004.

\footnotetext{
${ }^{1}$ Doutor em Filosofia, História da Educação/FE - UNICAMP. Professor do Curso de Pedagogia e do Programa de Pós-graduação/Mestrado em Educação da UNIOESTE, Campus Cascavel. Pós-doutorando em educação pela Universidade Estadual do Sudoeste da Bahia - UESB. Membro do grupo de pesquisa HISTEDOPR - História, sociedade e educação - Oeste do Paraná. E-mail: joao.silva@ unioeste.br

${ }^{2}$ Doutor em Educação pela Faculdade de Educação da Universidade Estadual de Campinas - Unicamp, área de pesquisa: Filosofia e Historia da Educação. Pós-doutorando pelo Programa de Pós-graduação em educação, UNIOESTE, Campus Cascavel. É vinculado ao Grupo de pesquisa HISTEDBR - Grupo de Pesquisa em História, Sociedade e Educação no Brasil - GT da Região Oeste do Paraná, HISTEDOPR. eraldo_batista@hotmail.com

${ }^{3}$ Graduada em Pedagogia,UNIOESTE - Universidade Estadual do Oeste do Paraná, Campus Cascavel. Mestranda em Educação, UNIOESTE, Campus Cascavel-Linha de Pesquisa: História da educação. Bolsista CAPES/UNIOESTE. Membro do grupo de pesquisa HISTEDOPR - História, sociedade e educação - Oeste do Paraná). E-mail: lidianemufatto@ hotmail.com

${ }^{4}$ Graduado em História. Mestrando em Educação na Universidade Estadual do Oeste do Paraná (UNIOESTE), campus de Cascavel//Bolsista CAPES/UNIOESTE - Linha de Pesquisa: História da educação. Email: ander1957@yahoo.com.br.
}

Recebido: $\quad$ setembro-15 Aprovado: outubro-15 